\title{
MODEL PENDUGA PENENTUAN KARYAWAN TELADAN BERBASIS ADAPTIVE NEURO FUZZY INFERENCE SYSTEM (ANFIS)
}

\author{
Nico Bustanul Anshary ${ }^{1}$, Nazori Az, M.T ${ }^{2}$ \\ Teknologi Sistem Informasi, Magister Ilmu Komputer, Universitas Budi Luhur \\ Jl. Ciledug Raya, Pertukangan Utara, Jakarta Selatan, 12260, Indonesia \\ nico.anshary@gmail.com¹, nazori@bl.ac.id ${ }^{2}$
}

\begin{abstract}
ABSTRAK
PT. Argha Karya merupakan perusahaan yang bergerak di bidang flexible packaging. Pada dasarnya untuk menentukan karyawan teladan belum digunakan suatu metode tertentu, khususnya metode logika fuzzy. Saat ini masih menggunakan hitungan manual, tetapi empat kriteria dalam penentuan karyawan teladan sudah menggunakan sistem. Empat kriteria tersebut adalah masa kerja, data kehadiran, efektifitas jam kerja dan penilaian kinerja. Logika fuzzy memiliki lebih dari satu metode dalam perhitungan perkiraan hasil suatu kasus tertentu. Kriteria penentuan karyawan teladan tersebut selanjutnya diolah dengan menggunakan permodelan berbasis Adaptive Neuro Fuzzy Inference System (ANFIS). Dalam proses pengolahan dibutuhkan data training, data testing dan data new. Nilai terendah yang didapat pada RMSE (Root Mean Square Error) data training adalah 1.5092e-06 dan data testing adalah 2.1437. Dengan bantuan software Matlab, maka dibuatlah suatu sistem pendukung keputusan dalam hal menentukan karyawan teladan dalam bentuk GUI (Grapical User Interface). Setelah sistem dibuat selanjutnya di uji menggunakan metode SQA (Software Quality Assurance). Hasil dari penelitian ini adalah dimana Penentuan Karyawan Teladan PT. Argha Karya Bogor objektif dan membuat keputusan yang lebih efektif dan efisien.
\end{abstract}

Kata Kunci: kinerja, Metode Adaptive Neuro Fuzzy Inference System, Matlab, data training, data testing, data new, SQA

\begin{abstract}
PT. Argha Karya is a company engaged in the flexible packaging. The company has not used a particular method, especially fuzzy logic method, to select the best employee. Even though the company is still using a manual calculation system, it has been adopting four criteria for selecting the best employee in a system. Those criteria are years of service, data of attendance, effectiveness of working hours and performance appraisal. Fuzzy logic has more than one method of calculating the estimated result of a particular case. The criteria for selecting the best employee are then processed applying modeling based on Adaptive Neuro Fuzzy Inference System. The process needs training data, testing data and new data. The lowest results of RMSE (Root Mean Square Error) for training data is 1.5092e-06 and for testing data is 2.1437. A decision supporting system for selecting the best employee in the form of GUI (Graphical User Interface) can be made with the help of Matlab software. Then, the established system will be evaluated using SQA (Software Quality Assurance) method. The result of this research shows the Selection of the Best Employee at PT Argha Karya Bogor is objective and the decisions made are more effective and efficient.

Keywords: performance appraisal, Adaptive Neuro Fuzzy Inference System Method, Matlab, training data, testing data, new data, SQA
\end{abstract}

\section{PENDAhUluan}

Penilaian kinerja Pegawai Swasta adalah penilaian secara periodik pelaksanaan pekerjaan seorang Pegawai Swasta. Tujuan penilaian kinerja adalah untuk mengetahui keberhasilan atau ketidak berhasilan seorang Pegawai Swasta, dan untuk mengetahui kekurangan-kekurangan dan kelebihan-kelebihan yang dimiliki oleh Pegawai Swasta yang bersangkutan dalam melaksanakan tugasnya. Hasil penilaian kinerja digunakan sebagai bahan pertimbangan dalam pembinaan Pegawai Swasta, antara lain pengangkatan, 
kenaikan pangkat, pengangkatan dalam jabatan, pendidikan dan pelatihan, serta pemberian penghargaan.

Dalam penilaian kinerja Pegawai Swasta diharapkan hasil yang didapat akurat dan benar adanya. PT. Argha Karya Prima Industry, Tbk adalah sebuah perusahaan yang telah memiliki sistem dalam penilaian, namun dalam menentukan karyawan teladan masih dilakukan secara manual, dimana bagian yang berwenang menilai menggunakan lembar penilaian, pada penilaian ini bisa mengakibatkan penilaian yang subyektif sehingga bisa menimbulkan ketidakadilan dalam penilaian.

Berdasarkan uraian tersebut maka diperlukan sebuah sistem yang memudahkan dalam menentukan karyawan teladan di PT. Argha Karya Prima Industry, Tbk dengan menggunakan metode Adaptive Neural Fuzzy Inference System (ANFIS).

Saat ini penentuan karyawan teladan pada PT. Argha Karya masih dilakukan secara subyektif dan manual oleh pihak berwenang. Cara tersebut kurang efisien dan efektif, oleh karena itu perlu metode yang praktis yang dapat diterapkan secara efesien dan efçktif dengan berdasarkan metode Adaptive Neural Fuzzy Inference System dan menggunakan tool Matlab R2011b.

Berdasarkan identifikasi masalah, dapat dirumuskan permasalahan sebagai berikut :

a. Bagaimana membuat atau membangun model sistem penentuan karyawan teladan berbasis Adaptive Neuro Fuzzy Inference System (ANFIS) dengan model Sugeno?

b. Bagaimana membangun program aplikasi penentuan karyawan teladan dalam format Graphical User Interface (GUI) menggunakan pernagkat lunak Matlab?

\section{Kinerja Karyawan}

Kinerja merupakan perwujudan kerja yang dilakukan oleh karyawan yang biasanya dipakai sebagai dasar penilaian terhadap karyawan atau organisasi. Kinerja yang baik merupakan langkah untuk tercapainya tujuan organisasi. Sehingga perlu diupayakan usaha untuk meningkatkan kinerja. Tetapi hal ini tidak mudah sebab banyak faktor yang mempengaruhi tinggi rendahnya kinerja seseorang ${ }^{[8]}$. Kinerja mengacu kepada kadar pencapaian tugastugas yang membentuk sebuah pekerjaan karyawan. Kinerja merefleksikan seberapa baik karyawan memenuhi persyaratan sebuah pekerjaan. Kinerja karyawan merupakan suatu hal yang sangat penting dalam upaya perusahaan untuk mencapai tujuannya. Dari beberapa uraian tersebut, dapat dikemukakan bahwa kinerja adalah hasil kerja nyata yang dicapai seseorang dalam melaksanakan tugas yang diberikan kepadanya sesuai dengan kriteria dan tujuan yang ditetapkan oleh organisasi.

\section{Sistem Pendukung Keputusan}

Sistem Pendukung Keputusan (Decision Support System) merupakan sistem yang berfungsi mentransformasi data dan informasi menjadi alternatif keputusan dan prioritasnya [1].

Komponen Keputusan [1]:

1. Alternatif Keputusan

2. Kriteria Keputusan

3. Bobot Kriteria

4. Model Penilaian

5. Struktur Keputusan

6. Model Penghitungan

\section{Logika Fuzzy}

Logika fuzzy merupakan salah satu komponen pembentuk soft computing. Logika fuzzy pertama kali diperkenalkan oleh prof. Lotfi A. Zadeh pada tahun 1965.

Logika fuzzy adalah suatu cara yang tepat untuk memetakan suatu ruang input ke dalam suatu ruang output [3]. Fuzzy dinyatakan dalam derajat dari suatu keanggotaan dan derajat dari kebenaran. Oleh sebab itu sesuatu dapat dikatakan 
sebagian benar dan sebagian salah pada waktu yang sama.

Ada beberapa alasan mengapa orang menggunakan logika fuzzy, antara lain:

1. Konsep logika fuzzy mudah dimengerti

2. Logika fuzzy sangat fleksibel

3. Logika fuzzy memiliki toleransi terhadap data-data yang tidak tepat

4. Logika fuzzy mampu memodelkan fungsi-fungsi nonlinier yang sangat kompleks.

5. Logika fuzzy dapat membangun dan mengaplikasikan pengalamanpengalaman para pakar secara langsung tanpa harus melalui proses pelatihan.

6. Logika fuzzy dapat bekerjasama dengan teknik-teknik kendali secara konvensional.

7. Logika fuzzy didasarkan pada bahasa alami [3].

\section{Metode Sugeno}

Penalaran dengan metode sugeno hampir sama dengan penalaran mamdani, hanya saja output (konsekuen) sistem tidak berupa himpunan fuzzy, melainkan berupa konstanta atau persamaan linear. Metode Sugeno diperkenalkan oleh Takagi-Sugeno Kang pada tahun 1985, sehingga ini sering juga dinamakan dengan metode TSK[4].

Metode TSK terdiri dari 2 jenis, yaitu :

1. Model fuzzy sugeno orde-nol

Secara umum bentuk model fuzzy sugeno orde-nol adalah :

IF $(\mathrm{x} 1$ is $\mathrm{A} 1) \cdot(\mathrm{x} 2$ is $\mathrm{A} 2) \cdot(\mathrm{x} 3$ is $\mathrm{A} 3)$ -......... $(x N$ is AN) THEN $z=k$

Dengan Ai adalah himpunan fuzzy ke-i sebagai anteseden, dan $\mathrm{k}$ adalah suatu konstanta (tegas) sebagai konsekuen

\section{Model fuzzy sugeno orde-satu}

Secara umum bentuk model fuzzy sugeno orde-satu adalah:

IF $(\mathrm{x} 1$ is $\mathrm{A} 1) \cdot \ldots \ldots \ldots \cdot(\mathrm{xN}$ is $\mathrm{AN})$ THEN $\mathrm{z}=\mathrm{p} 1 * \mathrm{x} 1+\ldots \ldots . .+\mathrm{pN} * \mathrm{xN}+\mathrm{q}$

Dengan Ai adalah himpunan fuzzy ke-i sebagai anteseden dan pi adalah suatu konstanta (tegas) ke-i dan $q$ juga merupakan konstanta dalam konsekuen. Apabila komposisi aturan menggunakan metode SUGENO, maka deffuzifikasi dilakukan dengan cara mencari nilai rataratanya.

\section{Adaptive Neuro Fuzzy Inference System(ANFIS)}

ANFIS (Adaptive Neuro Fuzzy Inference System atau Adaptive Network-based Fuzzy Inference System) adalah arsitektur yang secara fungsional sama dengan fuzzy rule base model Sugeno. Arsitektur ANFIS juga sama dengan jaringan syaraf dengan fungsi radial dengan sedikit batasan tertentu ${ }^{[4]}$. ANFIS adalah suatu metode yang mana dalam melakukan penyetelan aturan digunakan algoritma pembelajaran terhadap sekumpulan data. Pada ANFIS juga memungkinkan aturanaturan untuk beradaptasi. Pada ANFIS, jaringan syaraf digunakan untuk mengimplementasikan Fuzzy Inference System.

Agar jaringan dengan fungsi basis radial ekuivalen dengan fuzzy berbasis model Sugeno orde 1 ini, diperlukan batasan [4]:

1. Aturan-aturan harus memiliki metode agregasi yang sama (rata-rata terbobot atau penjumlahan terbobot) untuk menghasilkan semua outputnya.

2. Jumlah fungsi aktivasi harus sama dengan jumlah aturan fuzzy (IFTHEN).

3. Jika ada beberapa input pada basis aturanya, maka tiap-tiap fungsi aktivasi harus sama dengan fungsi keanggotaan tiap-tiap inputnya.

4. Fungsi aktivasi dan aturan-aturan fuzzy harus memiliki fungsi yang sama untuk neuron-neuron dan aturan-aturan yang ada di sisi outputnya.

\section{Perangkat Lunak Matlab R2011b}

Matlab merupakan bahasa pemrograman dengan kemampuan tinggi dalambidang komputasi. Saat ini, bahasa pemrograman tidak hanya dituntut memiliki kemampuan dari segi komputasi, tetapi juga kemampuan visualisasi yang baik [2]. 
Matlab memiliki kemampuan mengintegrasikan komputasi, visualisasi dan pemrograman. Dalam menvisualisasikan sebuah obyek, Matlab memiliki kemampuan merotasi obyek tanpa merubah programnya.

Fitur utama Matlabdalam membuat visualisasi obyek adalah Guide.[2]. Guide atau GUI Builder merupakan sebuah Graphical User Interface (GUI) yang dibangun dengan obyek grafis seperti tombol (button), kotak teks, slider,sumbu (axes) maupun menu.

\section{Software Quality Assurance (SQA)}

Software Quality Assurance (SQA) sebenarnya adalah untuk menghasilkan suatu produk perangkat lunak (software) yang berkualitas tinggi. SQA merupakan serangkaian aktifitas yang sistematik dan terencana dalam rangka memastikan kualitas software [5].

Software Quality Assurance (SQA) bertujuan untuk menghasilkan suatu produk software berkualitas tinggi.

SQA meliputi beberapa konsep sebagai berikut:

1. Pendekatan kualitas manajemen,

2. Teknologi rekayasa perangkat lunak yang efektif (metode dan tools yang digunakan),

3. Tinjauan teknis secara formal yang diaplikasikan melalui proses pengembangan software,

4. Strategi uji coba software yang multitier,

5. Kontrol terhadap dokumentasi software dan perubahannya,

6. Prosedur untuk memastikan pemenuhan standar pengembangan software, jika software tersebut diaplikasikan,

7. Mekanisme pengukuran dan laporan.

\section{Hipotesis Penelitian}

Hipotesis penelitian yang diajukan adalah : Diduga bahwa model penentuan karyawan teladan pada PT. Argha Karya dapat dibangun dengan menggunakan metode
Adaptive Neural Fuzzy Inference System (ANFIS) dan menggunakan software Matlab R2011B sehingga dapat lebih akurat.

\section{METODE PENELITIAN}

Penelitian ini menggunakan metode analisis kuantitatif. Untuk mendapatkan gambaran yang lebih mendalam danlengkap dari objek yang akan diteliti dengan melakukan pengamatan langsung di lapangan.

1. Penelitian Pendahuluan

Penelitian ini dilakukan untuk memperoleh kriteria-kriteria dalam penelitian, kriteria untuk menentukan karyawan teladan diperoleh dari pedoman prosedur manual Human Resource Dept.

2. Data Electronic Human Resource

Setelah memperoleh kriteria-kriteria, semesta pembicaraan, dan domain dari penelitian pendahuluan, selanjutnya akan diambil data dari sistem human resource yang sudah ada.

3. Mengelola hasil data EHR

Data yang diperoleh dari EHR akan diolah menggunakan pendekatan logika fuzzy dengan tool matlab.

Data yang diperoleh kemudian dimasukkan sebagai input dari Adaptive Neuro Fuzzy Inference Sistem (ANFIS), Sedangkan output nya adalah Karyawan Teladan, Calon Teladan dan Tidak Teladan.

\section{Metode Pemilihan Sampel}

Proses pemilihan sampel dilakukan dengan cara pengamatan langsung. Pemilihan sampel berdasarkan data karyawan 2013 dan 2014. Sampel pada penelitian ini adalah sebagian karyawan yang bekerja pada PT. Argha Karya yang berjumlah 73, sehingga data yang terkumpul 106 data. Berikut adalah variable-variabel yang digunakan dalam penelitian ini berdasarkan pedoman penentuan karyawan teladan tahun 2014 yang dikeluarkan oleh Human Resource Dept. 
Tabel 1. Tabel Variabel

\begin{tabular}{cl}
\hline Fungsi & \multicolumn{1}{c}{ Nama Variabel } \\
\hline & Masa Kerja \\
& Data Kehadiran \\
Input & Efektifitas Jam Kerja \\
& Penilaian Kinerja \\
\hline Output & Penentuan Karyawan Teladan \\
\hline
\end{tabular}

\section{Metode Pengumpulan Data}

Metode Pengumpulan data dilakukan secara langsung dengan menggunakan

\section{Data Primer}

Data primer merupakan sumber data penelitian yang diperoleh secara langsung dari sumber asli. Data primer penelitian diperoleh dengan cara observasi, wawancara dan kuesioner. Data dicatat dan dikumpulkan untuk kemudian dilakukan persiapan data.

2. Data Sekunder

Data sekunder merupakan sumber data penelitian yang diperoleh secara tidak langsung melalui media perantara. Data yang diperoleh secara tidak langsung, misalnya dari literature, dokumentasi, buku, jurnal dan informasi lainnya yang berhubungan dengan guru berprestasi dan ANFIS.

\section{HASIL DAN PEMBAHASAN Pengelompokan dan Analisis Data}

Data penelitian dibagi dalam tiga kelompok, yaitu:

a. 42 data pertama digunakan sebagai Training-Data (Data Pembelajaran)

b. 42 data kedua digunakan sebagai Testing-Data (Data Penguji Validitas)

c. 24 data ketiga digunakan sebagai NewData (Data Penerapan Model/Demo)

\author{
Simulasi Adaptive Neuro Fuzzy \\ Inference System (ANFIS) \\ Tahapan Proses Simulasi : \\ a. Tahap Load Data (Tahap Memasukkan \\ Data) \\ b. Tahap Generate FIS (Tahap \\ Membangkitkan FIS) \\ c. Tahap Train FIS (Tahap Pembelajaran \\ FIS) \\ d. Tahap Test FIS (Tahap Validasi FIS)
}

\section{Tahap Load Data}

Tahap ini merupakan tahap untuk me-load data baik data training maupun datatesting. Adapun untuk memasukkan kedua jenis data tersebut dapat dilakukan dengan cara melakukan load data dari dalam file yang tersimpan didalam komputer.

a. Input Data Pembelajaran (TrainingData)

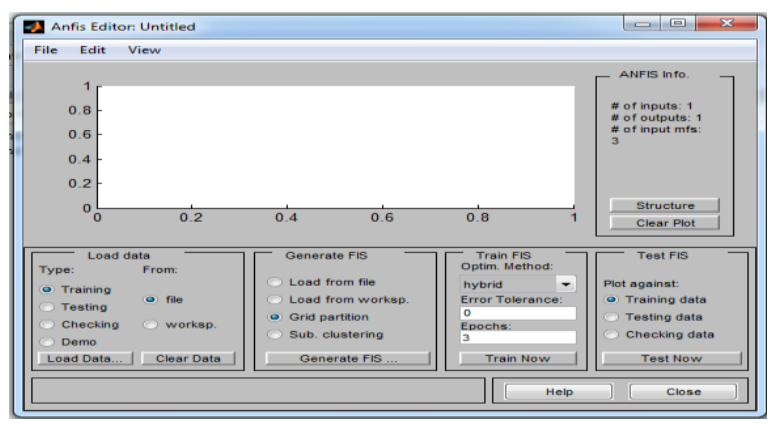

Gambar 1. Input Data Pembelajaran

Gambar 1 terdapat kolom load data dari dalam File yang tersimpan di dalam komputer, pilih option training lau pilih data pembelajaran (training) yaitu train data lalu pilih file data pembelajaran (training) yaitu train data.dat (sebanyak 42 data).

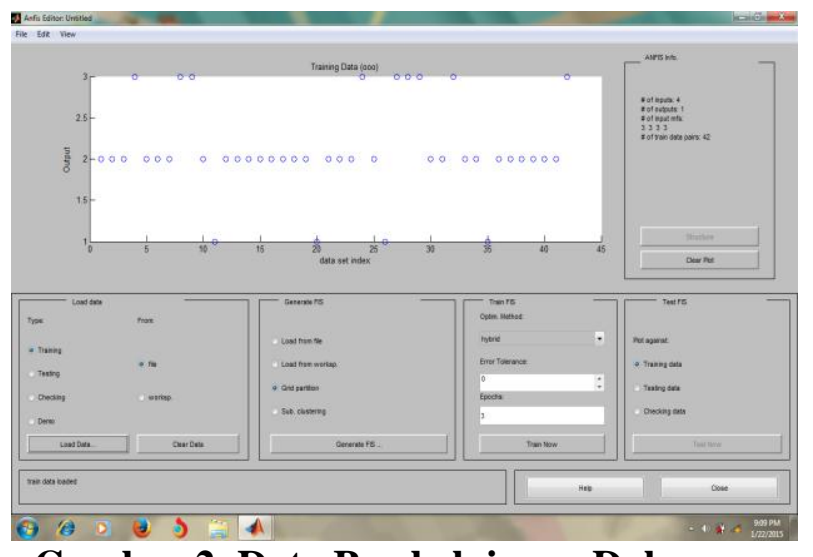

\section{Gambar 2. Data Pembelajaran Dalam Memori}

Pada gambar 2 diperlihatkan bentuk dan pelatihan yang telah diload kedalam ANFIS Editor GUI.Setelah data pembelajaran (training) yng telah diunggah dan disimbolkan dalam bentuk lingkaran kecil berlubang. 
b. Input Data Pengujian (Testing dan Validasi)

Setelah menggugah data pembelajaran (training), selanjutnya mengggah data pengujian (testing). Pada gambar 4-3 terdapat kolom load data dari dalam file yang tersimpan di dalam komputer, pilih option testing lalu pilih file data pembelajaran (testing) yaitu testing data.dat (sebanyak 42 data).

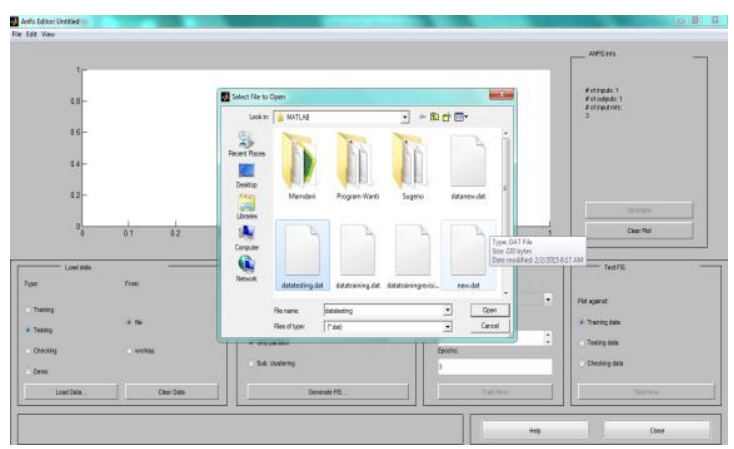

Gambar 3. Input Data Pengujian

Gambar 3 menunjukkan proses memasukkan data untuk keperluan proses pembelajaran dengan nama file testing data.dat, sedangkan gambar 4-4 menunjukkan Testing Data (Data Pengujian) yang telah berada dalam memori, disimbolkan dalam lingkaran kecil.

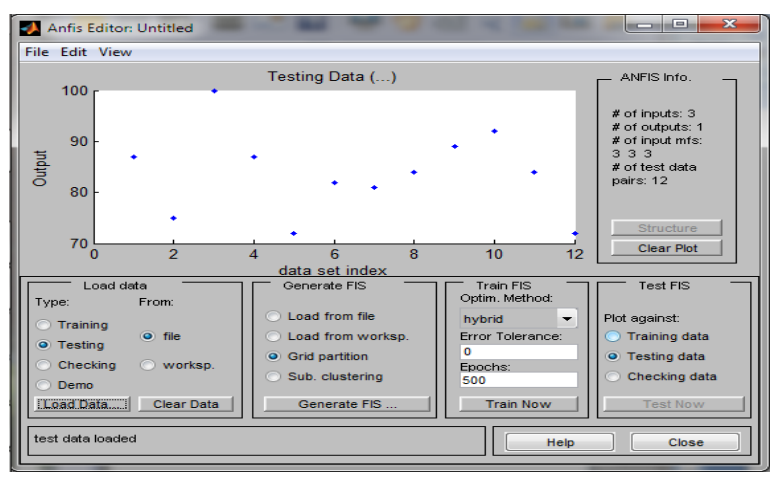

Gambar 4. Data Pengujian Dalam Memori

\section{Tahap Generate FIS (Fuzzy Inference System)}

Jumlah fungsi keanggotaan yang akan digunakan adalah (l $\left.\begin{array}{llll}3 & 3 & 3 & 3\end{array}\right)$. Tipe keanggotaan yang akan diujicoba dalam penelitian ini adalah tipe keanggotaan segitiga (trimf), trapesium (trapmf), lonceng (gbellmf) dan Gaussian (gaussmf).

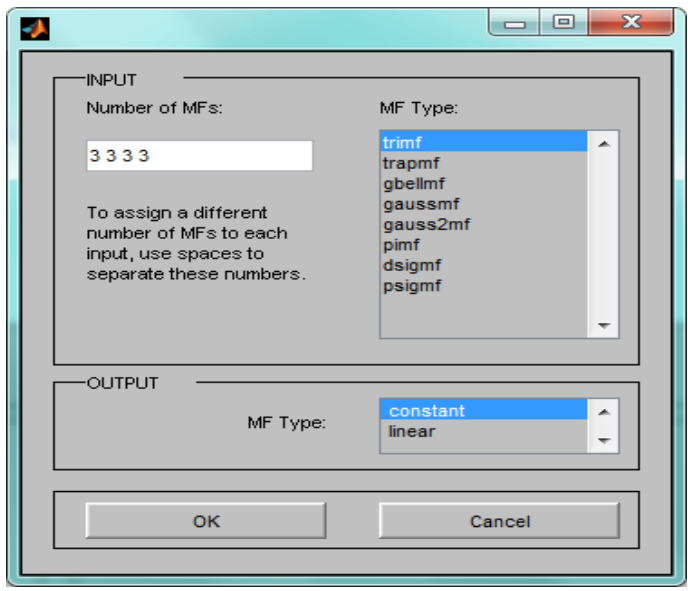

\section{Gambar 5. Generate FIS Membership} Function (MF) constant

Pada gambar 4-5 menunjukkan generate FIS membership Function (MF) dengan MF Type constant.

Tahap Training FIS (Tahap Pembelajaran FIS)

Tahap ini dilakukan untuk melihat tingkat error pada ANFIS

\section{a. Tahap Training FIS hybrid trimf}

Berdasarkan FIS yang akan dibangun maka dilakukan proses Training dengan epoch $=$ 500. Simulasi Algoritma Hybrid dengan fungsi "trimf", dengan jumlah MF [3 $\left.\begin{array}{llll}3 & 3 & 3 & 3\end{array}\right]$, fungsi MF output adalah tipe "constant"

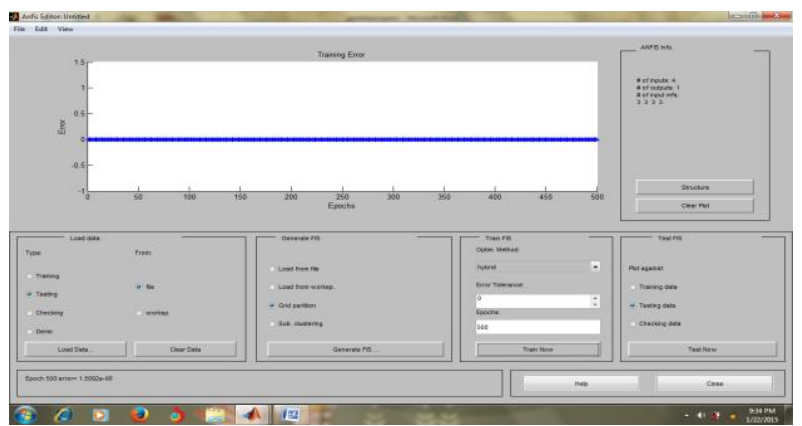

Gambar 6. Training Trimf dengan Algoritma Hybrid

Pada gambar 6 menunjukkan terjadinya proses pembelajaran untuk simulasi metode hybrid dengan fungsi keanggotaan "trimf". Nilai kwadrat rata-rata RMSE = $1,5092 \mathrm{e}-06$. 
b. Tahap Training FIS hybrid tramf

Berdasarkan FIS yang akan dibangun maka dilakukan proses Training dengan epoch $=500$. Simulasi Algoritma Hybrid dengan fungsi "tramf", dengan jumlah MF [3 3 3 $]$, fungsi MF output adalah tipe "constant"

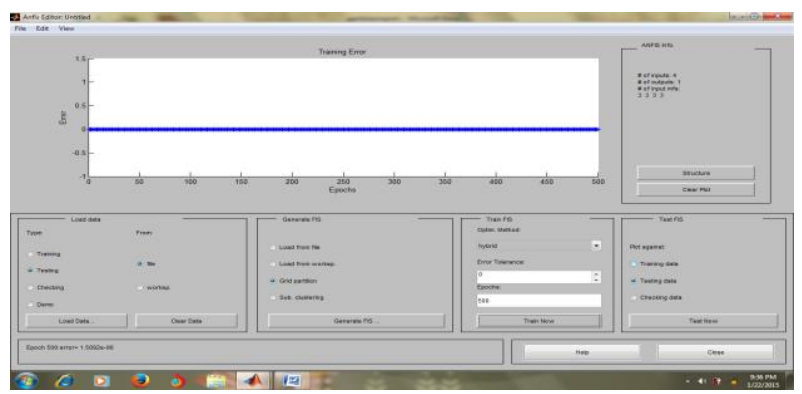

\section{Gambar 7. Training Trampf dengan Algoritma Hybrid}

Pada gambar 7 menunjukkan terjadinya proses pembelajaran untuk simulasi metode hybrid dengan fungsi keanggotaan "tramf". Nilai kwadrat rata-rata RMSE = $1,0952 \mathrm{e}-06$

c. Tahap Training FIS hybrid gbellmf Berdasarkan FIS yang akan dibangun maka dilakukan proses Training dengan epoch $=500$. Simulasi Algoritma Hybrid dengan fungsi "gibellmf", dengan jumlah MF [ [ $\left.\begin{array}{llll}3 & 3 & 3 & 3\end{array}\right]$, fungsi MF output adalah tipe "constant"

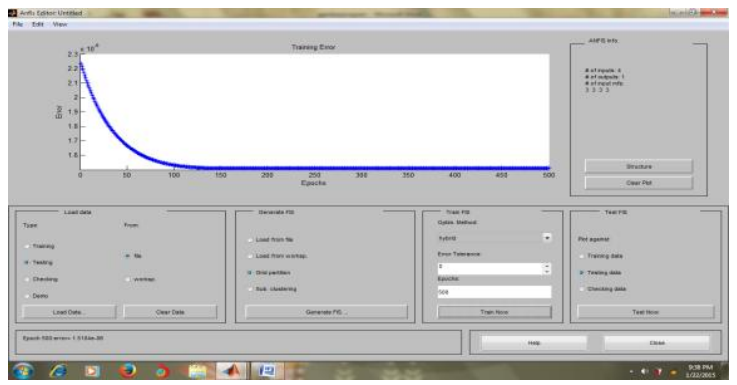

\section{Gambar 8. Training Gibellmf dengan Algoritma Hybrid}

Pada gambar 8 menunjukkan terjadinya proses pembelajaran untuk simulasi metode hybrid dengan fungsi keanggotaan "gbellmf". Nilai kwadrat rata-rata RMSE = 1,5104e-06. d. Tahap Training FIS hybrid gaussmf

Berdasarkan FIS yang akan dibangun maka dilakukan proses Training dengan epoch $=500$. Simulasi Algoritma Hybrid dengan fungsi "gibellmf", dengan jumlah MF [ [ $\left.\begin{array}{llll}3 & 3 & 3 & 3\end{array}\right]$, fungsi MF output adalah tipe "constant"

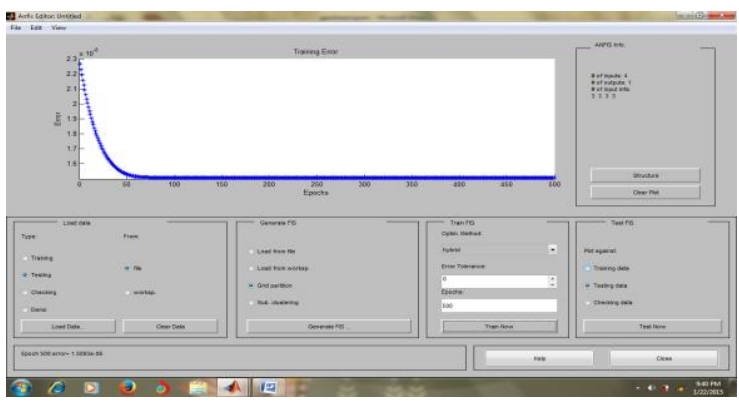

\section{Gambar 9. Training Gaussmf dengan Algoritma Hybrid}

Pada gambar 11 menunjukkan terjadinya proses pembelajaran untuk simulasi metode hybrid dengan fungsi keanggotaan "gaussmf". Nilai kwadrat rata-rata RMSE $=1,5093 \mathrm{e}-06$

e. Tahap Training FIS backpropagation trimf Berdasarkan FIS yang akan dibangun maka dilakukan proses Training dengan epoch $=$ 500. Simulasi Algoritma Backpropagation dengan fungsi "trimf", dengan jumlah MF [ $\left[\begin{array}{llll}3 & 3 & 3 & 3\end{array}\right]$, fungsi MF output adalah tipe "constant"

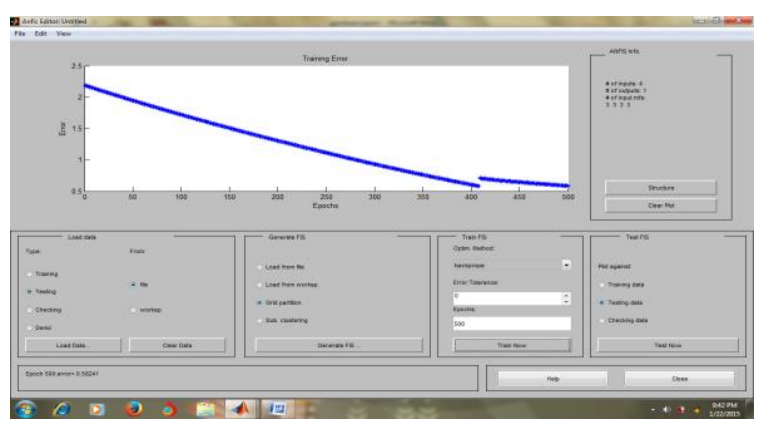

\section{Gambar 10. Training Trimf dengan Algoritma Backpropagation}

Pada gambar 12 menunjukkan terjadinya proses pembelajaran untuk simulasi metode backpropagation dengan fungsi keanggotaan "trimf". Nilai kwadrat ratarata $\mathrm{RMSE}=0,58241$ 
f. Tahap Training FIS backpropagation tramf

Berdasarkan FIS yang akan dibangun maka dilakukan proses Training dengan epoch $=$ 500. Simulasi Algoritma Backpropagation dengan fungsi "tramf", dengan jumlah MF [ [ $\left.\begin{array}{llll}3 & 3 & 3 & 3\end{array}\right]$, fungsi MF output adalah tipe "constant"

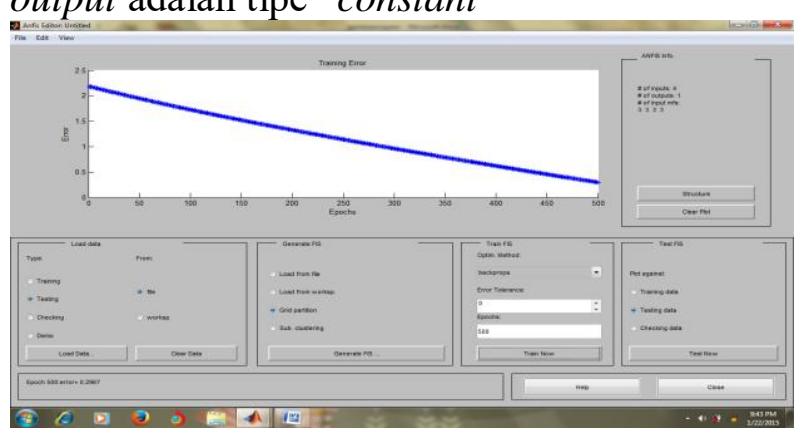

Gambar 11. Training Tramf dengan Algoritma Backpropagation

Pada gambar 13 menunjukkan terjadinya proses pembelajaran untuk simulasi metode backpropagation dengan fungsi keanggotaan "tramf". Nilai kwadrat ratarata $\mathrm{RMSE}=0,2967$

g. Tahap Training FIS backpropagation gbellmf

Berdasarkan FIS yang akan dibangun maka dilakukan proses Training dengan epoch $=$ 500. Simulasi Algoritma Backpropagation dengan fungsi "gibellmf", dengan jumlah MF [ [ $\left.\begin{array}{llll}3 & 3 & 3 & 3\end{array}\right]$, fungsi MF output adalah tipe "constant"

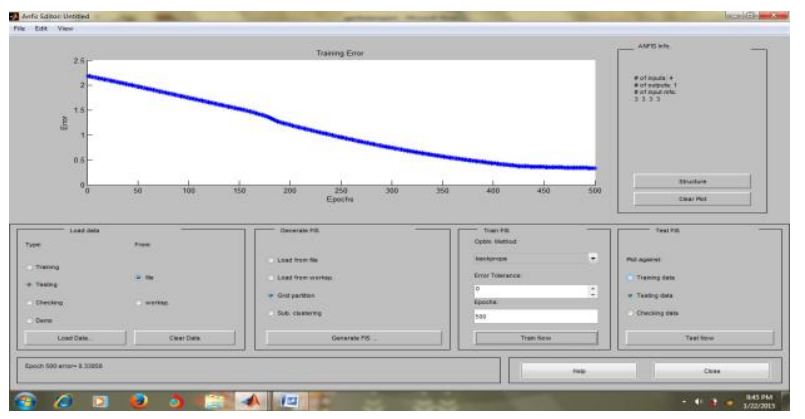

Gambar 12. Training Gbellmf dengan Algoritma Backpropagation

Pada gambar 14 menunjukkan terjadinya proses pembelajaran untuk simulasi metode backpropagation dengan fungsi keanggotaan "gbellmf". Nilai kwadrat ratarata $\mathrm{RMSE}=0,33858$

h. Tahap Training FIS backpropagation gaussmf

Berdasarkan FIS yang akan dibangun maka dilakukan proses Training dengan epoch $=$ 500. Simulasi Algoritma backpropagation dengan fungsi "gibellmf", dengan jumlah MF [ [ $\left.\begin{array}{llll}3 & 3 & 3 & 3\end{array}\right]$, fungsi MF output adalah tipe "constant"

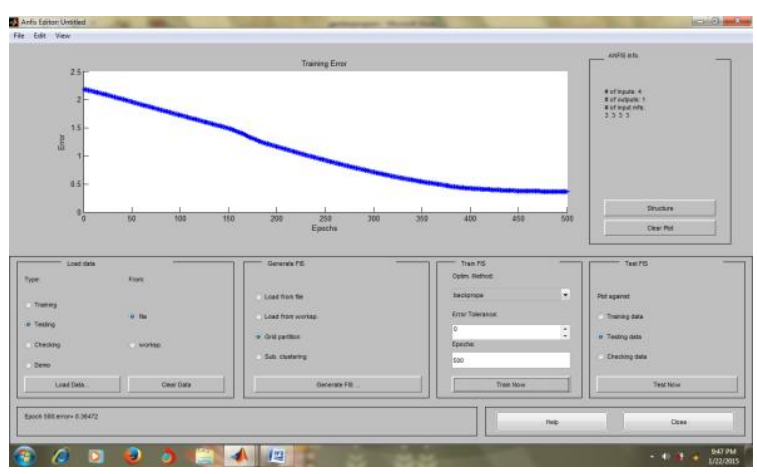

\section{Gambar 13. Training Gaussmf Dengan} Algoritma Backpropagation

Pada gambar 13 menunjukkan terjadinya proses pembelajaran untuk simulasi metode backpropagation dengan fungsi keanggotaan "gaussmf". Nilai kwadrat rata-rata $\mathrm{RMSE}=0,36472$

\section{Tahap Testing FIS (Tahap Validasi} FIS)

Langkah selanjutnya memvalidasi data FIS.

a. Tahap Testing FIS Hybrid trimf Tahap Testing FIS Hybrid trimf

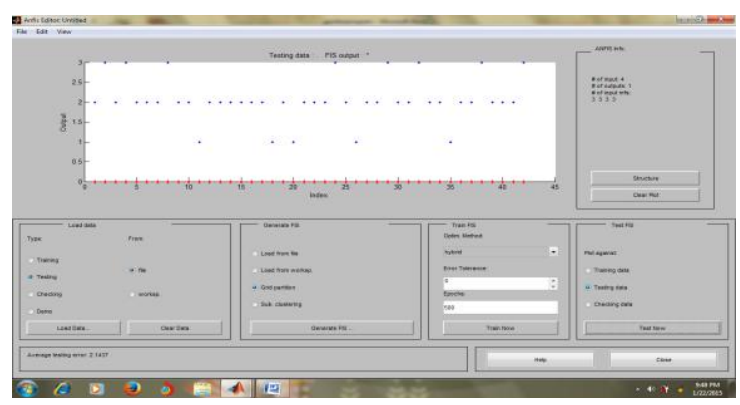

\section{Gambar 14. Testing Trimf Dengan} Algoritma Hybrid

Pada gambar 14 Menunjukkan terjadinya proses pembelajaran untuk simulasi metode hybrid dengan fungsi keanggotaan 
"trimf". Dan setelah diuji validasi testing data dengan epoch 500 dihasilkan kesalahan kwadrat rata-rata RMSE = 2,1437

b. Tahap Testing FIS Hybrid trapmf Tahap Testing FIS Hybrid trapmf

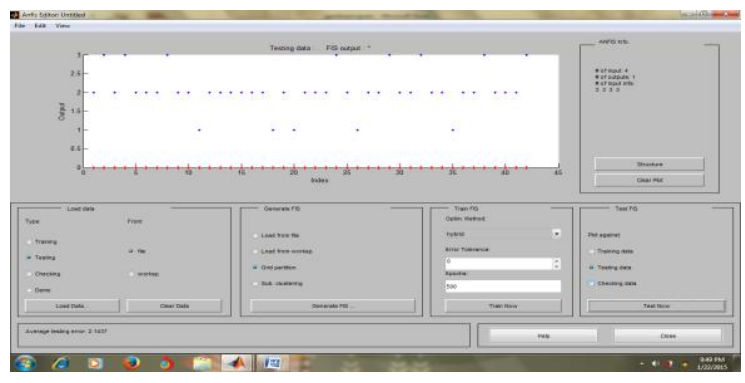

Gambar 15. Testing Trapmf Dengan Algoritma Hybrid

Pada gambar 15 Menunjukkan terjadinya proses pembelajaran untuk simulasi metode hybrid dengan fungsi keanggotaan "trapmf". Dan setelah diuji validasi testing data dengan epoch 500 dihasilkan kesalahan kwadrat rata-rata $\mathrm{RMSE}=$ 2,1437

c. Tahap Testing FIS Hybrid gbellmf Tahap Testing FIS Hybrid gbellmf

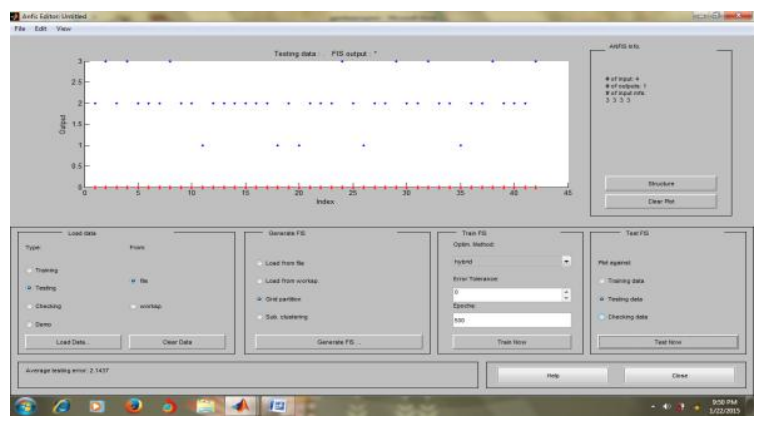

\section{Gambar 16. Testing Gbellmf Dengan} Algoritma Hybrid

Pada gambar 16 Menunjukkan terjadinya proses pembelajaran untuk simulasi metode hybrid dengan fungsi keanggotaan "gbellmf". Dan setelah diuji validasi testing data dengan epoch 500 dihasilkan kesalahan kwadrat rata-rata RMSE = 2,1437

d. Tahap Testing FIS Hybrid gaussmf Tahap Testing FIS Hybrid gaussmf

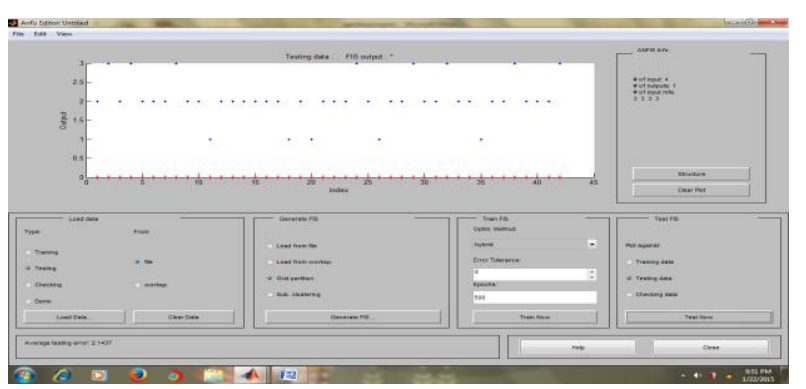

\section{Gambar 17. Testing Gaussmf dengan Algoritma Hybrid}

Pada gambar 17 Menunjukkan terjadinya proses pembelajaran untuk simulasi metode hybrid dengan fungsi keanggotaan "gaussmf". Dan setelah diuji validasi testing data dengan epoch 500 dihasilkan kesalahan kwadrat rata-rata $\mathrm{RMSE}=$ 2,1437

e. Tahap Testing FIS Backpropagation trimf

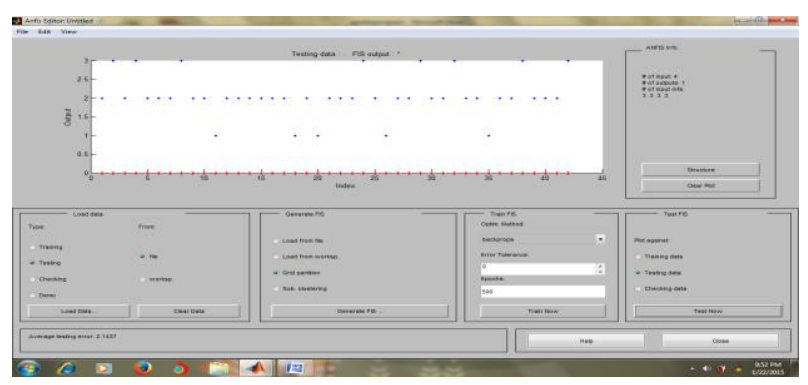

\section{Gambar 18. Testing Tripmf dengan Algoritma Backpropagation}

Pada gambar 18 Menunjukkan terjadinya proses pembelajaran untuk simulasi metode dengan fungsi keanggotaan "trimf". Dan setelah diuji validasi testing data dengan epoch 500 dihasilkan kesalahan kwadrat rata-rata RMSE = 2,1437

$f$. Tahap Testing FIS Backpropagation tramf

Tahap Testing FIS Backpropagation tramf 


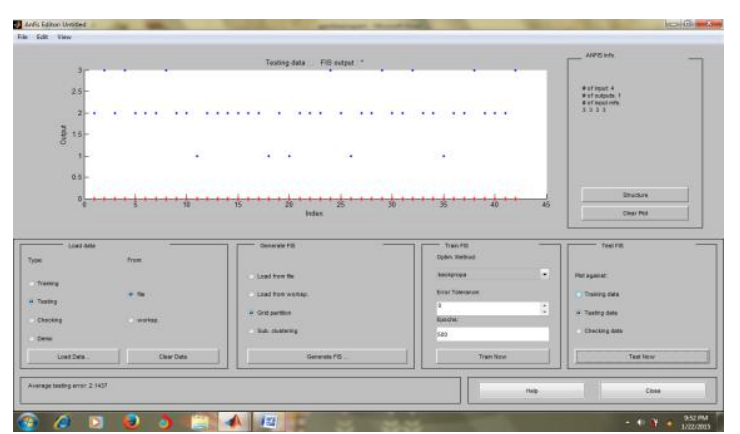

Gambar 19. Testing Trapmf dengan Algoritma Backpropagation

Pada gambar 19 Menunjukkan terjadinya proses pembelajaran untuk simulasi metode dengan fungsi keanggotaan "tramf". Dan setelah diuji validasi testing data dengan epoch 500 dihasilkan kesalahan kwadrat rata-rata $\mathrm{RMSE}=$ 2,1437

g. Tahap Testing FIS Backpropagation gbellmf

Tahap Testing FIS Backpropagation gbellmf

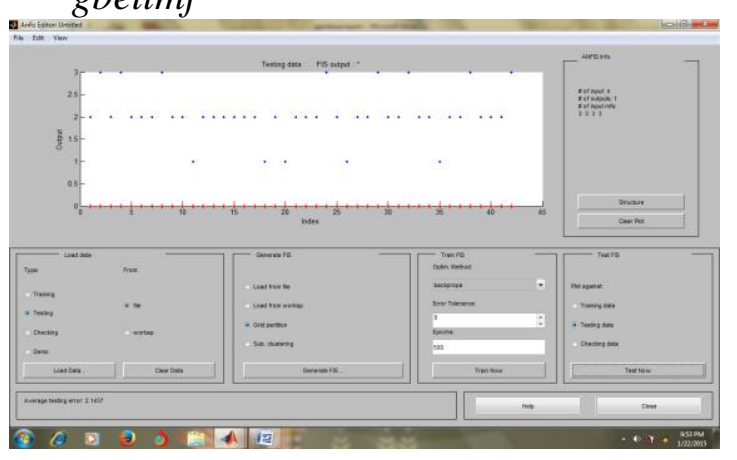

Gambar 20. Testing Gbellmf dengan Algoritma Backpropagation

Pada gambar 20 Menunjukkan terjadinya proses pembelajaran untuk simulasi metode dengan fungsi keanggotaan "gbellmf". Dan setelah diuji validasi testing data dengan epoch 500 dihasilkan kesalahan kwadrat rata-rata RMSE = 2.1437

h. Tahap Testing FIS Backpropagation gaussmf

Tahap Testing FIS Backpropagation gaussllmf

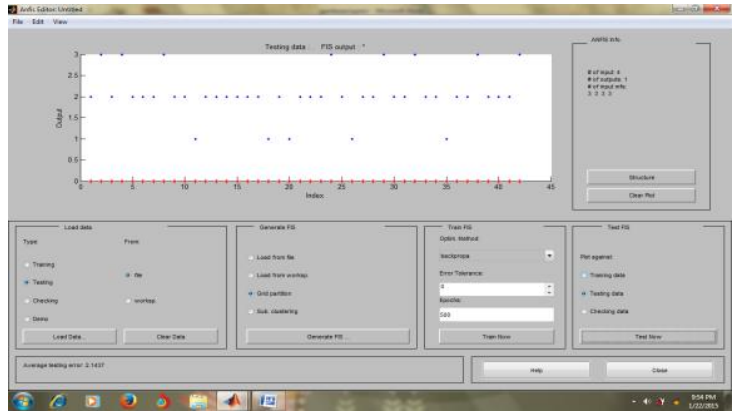

Gambar 21. Testing Gaussmf dengan Algoritma Backpropagation

Pada gambar 21 Menunjukkan terjadinya proses pembelajaran untuk simulasi metode dengan fungsi keanggotaan "gaussmf". Dan setelah diuji validasi testing data dengan epoch 500 dihasilkan kesalahan kwadrat rata-rata $\mathrm{RMSE}=$ 2,1437

\section{Hasil Pengujian Simulasi ANFIS}

Berdasarkan simulasi ANFIS yang dilakukan, maka didapatkan hasil simulasi berdasarkan metode yang digunakan, yaitu metode Hybrid dan Backpropagation, dan juga berdasarkan kategori variabel dari tipe $\mathrm{MF}$ (Membership Function).

\section{Tabel 2. Perbandingan RMSE Data} Training dengan Data Testing

\begin{tabular}{|l|l|l|l|l|}
\hline \multirow{2}{*}{$\begin{array}{c}\text { Member } \\
\text { Function }\end{array}$} & \multicolumn{2}{|l|}{ RMSE Data Training } & \multicolumn{2}{l|}{ RMSE Data Testing } \\
\cline { 2 - 5 } & Hybrid & $\begin{array}{c}\text { Backprop } \\
\text { agation }\end{array}$ & Hybrid & $\begin{array}{c}\text { Backpro } \\
\text { pagation }\end{array}$ \\
\hline Trimf & $\begin{array}{l}1.5092 \mathrm{e} \\
-06\end{array}$ & 0.58241 & 2.1437 & 2.1437 \\
\hline Trapmf & $\begin{array}{l}1.5092 \mathrm{e} \\
-06\end{array}$ & 0.29670 & 2.1437 & 2.1437 \\
\hline Gbellmf & $1.5104 \mathrm{e}$ & 0.33858 & 2.1437 & 2.1437 \\
& -06 & & & \\
\hline Gaussmf & $1.5093 \mathrm{e}$ & 0.36472 & 2.1437 & 2.1437 \\
& -06 & & & \\
\hline
\end{tabular}

Pada table 2 menunjukkan perbandingan RMSE untuk kedua metode yaitu Hybrid dan Backpropagation pada proses pembelajaran (training) dan proses validasi (testing). RMSE terendah pada proses pembelajaran yaitu $1.5092 \mathrm{e}-06$ 
dengan fungsi keanggotaan trimf dan trimf

\section{Interpretasi}

Model Proses Pembelajaran (Training)

Berdasarkan perbandingan RMSE (Root Mean Square Error) proses pembelajaran (training) pada table 2 metode yang paling optimal untuk kasus ini adalah :

a. Algoritma Pembelajaran : Metode Hybrid

b. Tipe Membership Function (MF) : trimf

c. Epoch : 500

d. Error tolerance : 0

e. ParameterInput : ( $\left.\begin{array}{llll}3 & 3 & 3 & 3\end{array}\right)$

f. Terdiri dari 81 rule

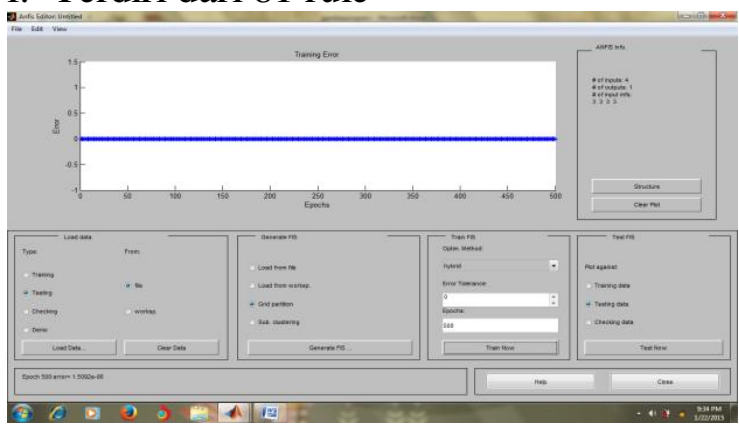

Gambar 22. Model Pembelajaran (Training) RMSE Terendah

Pada gambar 22 menunjukan bahwa model pembelajaran (training) terdapat pada metode Hybrid dengan tipe membership fuction trimfdengan menghasilkan error $=1,5092 \mathrm{e}-06$

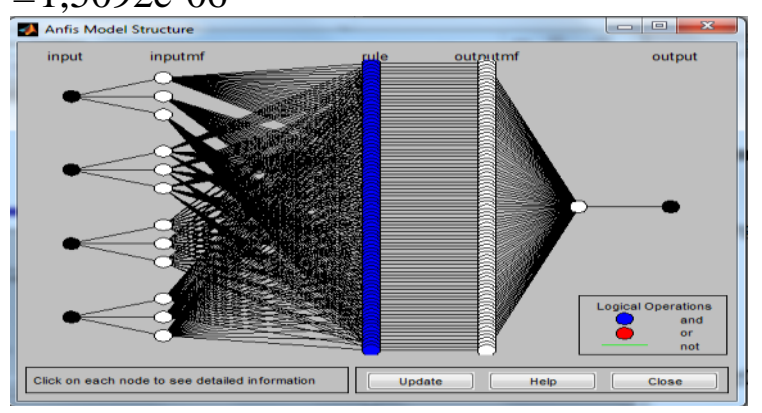

\section{Gambar 23. Model Structure} Pembelajaran (Training)

Pada gambar 23 menunjukkan neuron ANFIS yang terdiri dari 4 masukan dan satu keluaran dan 81 rules. Data yang telah diproses tersebut disimpan dalam bentuk fis dengan nama file Aplikasi.fis. Untuk menyimpan hasil olahan data tersebut pilih File-Export-ToFile agar lebih permanen. Untuk menampilkan FIS data ketikan:> fuzzy nama_file.fis pada command yang ada di matlab.

Contoh: fuzzy Aplikasi.fis

Kemudian akan muncul jendela FIS editor seperti gambar 24. Jendela FIS

Editor digunakan untuk memperjelas FIS hasil training ANFIS. Kotak berwarna kuning menunjukan parameter masukan, kotak putih menunjukan rule ANFIS, dan kotak hijau menunjukan keluaran.

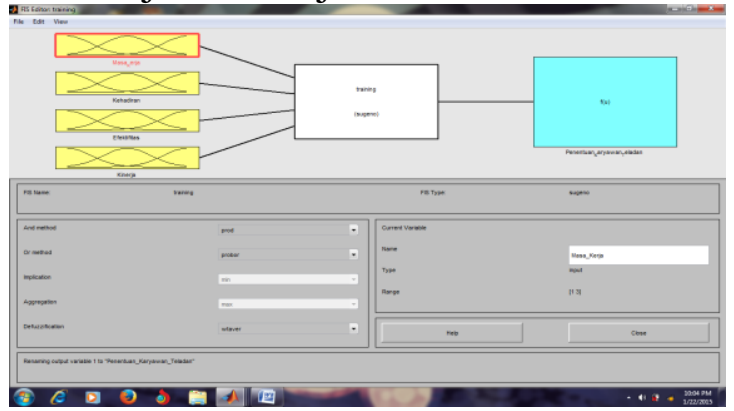

\section{Gambar 24. FIS Editor Pembelajaran (Training)}

Pada gambar 24 merupakan bentuk FIS editor pembelajaran (training).Double klik pada masing-masing parameter untuk menampilkan editor fungsi keanggotaan. Selanjutnya akan muncul membership function plots seperti gambar 4.26 .

\section{GUI (Graphical User Interface)}

Tampilan dari Model Penentuan Karyawan Teladan Berbasis Adaptive Neuro Fuzzy Inference ini menggunakan software Matlab R2011b, dengan output Karyawan Teladan, Calon Teladan dan Tidak Teladan. Rule yang dipakai adalah dari rule ANFIS dengan fungsi logika AND. Tampilan dari Model Penentuan Karyawan Teladan Berbasis Adaptive Neuro Fuzzy Inference terlihat pada gambar berikut. 


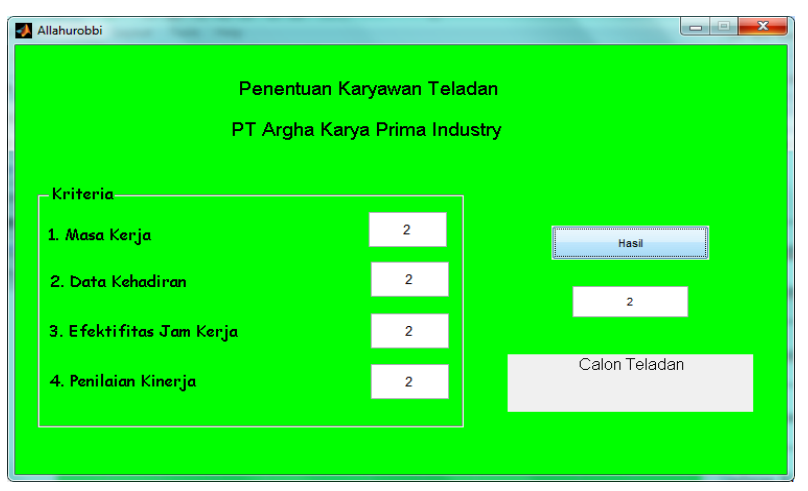

Gambar 25. Tampilan GUI Model Penentuan Karyawan Teladan

\section{Pengujian Data/Sistem/Prototipe Model}

Untuk memastikan bahwa perangkat lunak yang dibuat memiliki suatu standar minimal kualitas, maka metoda yang akan dipakai untuk pengukuran perangkat lunak secara kuantitatif pada penelitian ini adalah dengan metoda SQA(Software Quality Assurance).

Tabel 3. Metric of Software Quality Assurance

\begin{tabular}{|c|c|c|c|c|c|c|c|c|c|}
\hline \multirow{2}{*}{ User } & \multicolumn{7}{|c|}{ Skor Metrik } & \multirow{2}{*}{ Skor } \\
\cline { 2 - 9 } & $\mathbf{1}$ & $\mathbf{2}$ & $\mathbf{3}$ & $\mathbf{4}$ & $\mathbf{5}$ & $\mathbf{6}$ & $\mathbf{7}$ & $\mathbf{8}$ & \\
\hline$\# 1$ & 85 & 80 & 78 & 90 & 80 & 89 & 80 & 89 & 88,25 \\
\hline$\# 2$ & 75 & 80 & 81 & 81 & 81 & 89 & 85 & 80 & 81.9 \\
\hline$\# 3$ & 78 & 79 & 82 & 75 & 85 & 79 & 79 & 80 & 79.55 \\
\hline$\# 4$ & 80 & 86 & 79 & 84 & 83 & 82 & 82 & 79 & 81.95 \\
\hline$\# 5$ & 80 & 80 & 81 & 85 & 83 & 79 & 80 & 81 & 80,9 \\
\hline & \multicolumn{7}{|c|}{ Rata-Rata } & & 82.51 \\
\hline
\end{tabular}

Berdasarkan hasil evaluasi penilaian kualitas perangkat lunak maka dapat diketahui bahwa dari 5 responden dengan 8 variabel penelitian, maka dapat diketahui bahwa dari 5 responden dengan 8 variabel penelitian, 4 diantaranya memperoleh nilai baik dan 1 responden penelitian memperoleh nilai cukup. Jika demikian maka secara umum aplikasi ini memiliki kualitas baik sehingga layak digunakan sebagai perangkat lunak untuk penentuan karyawan teladan.

\section{SIMPULAN}

Dari hasil simulasi ANFIS yang dilakukan dengan Matlab dan menggunakan algoritma hybrid dan backpropagation serta proses pembelajaran dan validasi yang dilakukan diperoleh nilai yang paling optimal dari proses pembelajaran menghasilkan RMSE 1.5092e-06 untuk model pelatihan yang paling optimal. Sedangkan pemodelan yang paling optimal untuk validasi menghasilkan nilai RMSE terendah 2,1437 dengan menggunakan metode hybrid dan backpropagation serta membership function trimf, trapmf,Gbellmf, gaussmf.

\section{DAFTAR PUSTAKA}

[1] Marimin dan Nurul Maghfiroh. Aplikasi Teknik Pengambilan Keputusan dalam Manajemen Rantai Pasok. Bogor: IPB Press. 2010.

[2] Widodo, P.P., dan Trias,H.R. Penerapan Soft Computing Dengan Matlab. Bandung: Rekayasa Sains. 2012.

[3] Widodo, P.P., \&Trias-Handayanto, Rahmadya, Herlawati. Penerapan Data Mining dengan Matlab. Bandung: Rekayasa Sains.2013.

[4] Proboyekti, Umi. Software Quality Assurance. Diakses pada tanggal 15 September 2014 pada http://lecturer.ukdw.ac.id/othie/sqa. pdf 